\title{
Context-aware Spatial Decision Support Systems (CA- SDSS): Articulating Decision Support Systems, Business Intelligence and Recommender Systems considering the geospatial component
}

\author{
Tatiana Delgado ${ }^{1}$, Guillermo González ${ }^{2}$, Giosvany Miranda ${ }^{3}$, David G. Navarro ${ }^{4}$, Ariel Graverán $^{1}$ \\ ${ }^{1}$ Polytechnic Institute José Antonio Echeverría, La Habana, Cuba \\ ${ }^{2}$ GEOCUBA, Villa Clara, Cuba \\ ${ }^{3}$ GEOCUBA, La Habana, Cuba \\ ${ }^{4}$ Informatic Science University, La Habana, Cuba \\ tdelgado@ind.cujae.edu.cu, guille@geomix.geocuba.cu, gmiranda@geosi.geocuba.cu, dgnavarro@uci.cu, agrave- \\ ran@ind.cujae.edu.cu
}

\begin{abstract}
Underpinned by the vertiginous progress of Informatics and Communication Technologies, new evolutions of decision technologies are coming with the consequent benefit for decision makers and users in general. The integration of Geographical Information Systems (GIS) and Decision Support Systems (DSS) attracted significant attention during the latest decades. Spatial DSS, Spatial Online Analytic Processing (SOLAP), Location Intelligence and Mobile GIS are illustrative examples. As foundational concepts of the approach discussed in this paper some differences and similarities among Decision Support Systems, Business Intelligence and Recommender Systems are revealed. To complement this conceptualizing the evolution of these decision systems within the framework of geospatial ones are also exposed. By integrating concepts from Spatial Decision Support Systems, Locationbased Services and Recommender Systems, a new generalized conceptual model of Context-aware Spatial Decision Support Systems (CA-SDSS) is provided.
\end{abstract}

Keywords: (Spatial) Decision Support Systems, (Geospatial) Business Intelligence, Context-aware Recommender Systems.

\section{Introduction}

Since the first Geographical Information Systems in the 60 `s decade of the past century, new analytic potentialities to equip them with better decision tools were being incorporated.

The idea of a Spatial Decision Support System (SDSS) evolved in the mid 1980's, and by the end of the decade, SDSS was included in an authoritative review of the GIS field [1]. By the early 1990's, these systems had achieved a recognized place in the GIS community and was identified by Muller [2] as a growth area in the application of GIS technology. More recently, Collaborative and Web Spatial Decision Support Systems [3], [4] and [5] have been developed accordingly with the evolution of the web.

Geospatial part of business data may be more suitably exploited if it is analyzed and represented by Business Intelligent Systems coupled with maps and GIS capabilities [6]. This geospatial-extended business intelligence is known as Geospatial Business Intelligence (GeoBI). Furthermore, GeoBI systems, by providing an intelligent coupling of geospatial and Business Intelligence technologies have specifically extended the capacity of data analysis by bringing spatio-temporal data support, cartographic visualization and spatial analysis capabilities [7]. The Open Geospatial Consortium (OGC) Board of Directors has identified Geospatial Business Intelligence (GeoBI) as a major focus area for OGC standards related activities. Increasing the uptake of OGC standards in the location intelligence marketplace and within the business enterprise can be a basis for improved decision making and opportunities for broader use of products that implement OGC standards [8].

Recommender Systems (RS) take into account user preferences to suggest information of potential interest to them. RS have begun to incorporate geographic components into decision making applications. This is expressed, for example, in the new trend of RS built on Location Based Services (LBS) and incorporated into mobile tourism guides to provide users with interesting points of interest according to their contextual information, mainly physical location [9]. In [10] a method of Spatial Semantic Context-Aware Recommender System is discussed. Context-aware Recommender Systems within the Location Based Services family points to become in strong decision tools in a more and more collaborative and semantic Web. 
This paper is aimed to describe a new conceptual model for Spatial Decision Support Systems that integrates traditional SDSS with key concepts from Business Intelligence and Context-aware Recommender Systems. The new conceptual model is identified by the term Context-aware Spatial Decision Support Systems (CA-SDSS).

First sections of the paper deal with concepts and components of Decision Support Systems, Business Intelligence and Recommender Systems to support the subsequent analysis of their relations, similarities and specificities. Then a big picture on a time line revealing the evolution of these technologies and systems from a geospatial perspective is discussed. The new approach of CA-SDSS is then described. And finally, the main findings and future work is summarized.

\section{Foundational concepts.}

Contradictory information about decision support tools are frequently employed by different communities (scientists, software developers, decision users, etc.). Whilst some people operate with the term Decision Support Systems (DSS) to explain tools for decision making, others use the term Business Intelligence (BI) for similar functionality. In parallel, new terms as Recommender Systems (RS) are arising to describe other field of decision making in collaborative (Web 2.0) contexts, but also including genetic characteristics of their predecessors.

\section{Decision Support Systems}

The history of the implementation of Decision Support Systems begins in the mid-1960s [11]. Some definitions of DSS are given by different authors [12], [13], [14], [15], [16], [17]. In short, a DSS is an information interactive system useful to solve non-patterned problems for decision making.

DSS decision-making processes start with the problem identification; once the problem is recognized, it is defined in terms that facilitate the creation of models. Alternative solutions are created, and models are then developed to analyze the various alternatives. The choice is then made and implemented consistent with Simon's description. Of course, no decision process is this clear-cut in an ill structured situation [18].

\section{Classification of DSS [11] [19] includes:}

Data driven DSS - includes file drawer and management reporting systems, data warehousing and analysis systems, Executive Information Systems (EIS) and Geographic Information Systems (GIS). Data-Driven DSS emphasize access to and manipulation of large databases of structured data and especially a time-series of internal company data and sometimes external data.
Model driven DSS - includes systems that use accounting and financial models, representational models, and optimization models. Model-Driven DSS emphasize access to and manipulation of a model.

Knowledge driven DSS - can suggest or recommend actions to managers. A related concept is Data Mining. It refers to a class of analytical applications that search for hidden patterns in a database. Data mining tools can be used to create hybrid Data-Driven and Knowledge-Driven DSS.

Document driven DSS - integrates a variety of storage and processing technologies to provide complete document retrieval and analysis. The Web provides access to large document databases including databases of hypertext documents, images, sounds and video.

Communication driven and group DSS - where communication driven DSS includes communication, collaboration and coordination and GDSS focus on supporting groups of decision makers to analyze problem situations and performing group decision making tasks.

\section{Business Intelligence}

The term intelligence has been used by researchers in artificial intelligence since the 1950s. Business intelligence became a popular term in the business and IT communities only in the 1990s. In the late 2000s, business analytics was introduced to represent the key analytical component in BI [20]. Business intelligence, which is defined as the result of "acquisition, interpretation, collation, assessment, and exploitation of information" [21], is getting the right information to the right people at the right time [22].

BI also includes the underlying architectures, tools, databases, applications, and methodologies [23]. BI's major objectives are to enable interactive and easy access to diverse data, enable manipulation and transformation of these data, and provide business managers and analysts the ability to conduct appropriate analyses and perform actions [24].

As a data-centric approach, BI heavily relies on advanced data collection, extraction, and analysis technologies [25] [24]. Data warehousing is the foundation of BI. The design of data marts and tools for extraction, transformation, and load (ETL) are essential for converting and integrating enterprise-specific data. Database query, online analytical processing (OLAP), and advanced reporting tools are often adopted next to explore important data characteristics. Business performance management using scorecards and dashboards can be used to analyze and visualize various employee performance metrics. In addition to these well-established business reporting functions, statistical analysis and data mining techniques are adopted for association analysis, data segmentation and clustering, classification and regression analysis, anomaly detection, and predictive modeling in various business 
applications. Most of these data processing and analytical technologies have already been incorporated into the leading commercial BI platforms offered by major IT vendors including Microsoft, IBM, Oracle, and SAP [26].

\section{Recommender Systems.}

Given the large amount of information available on the Web and in some services provided therein, as processes or marketing sales in recent years have been developing and implementing various tools to provide users quick access and appropriate information needed [27]. Recommender Systems have emerged strongly in this area, as tools whose mission is customize the information that users receive according to their needs, preferences and / or tastes. Because of its success, there is a wide spectrum of applications of recommender systems [28], especially for e-commerce and entertainment.

Recommender systems take into account user preferences to suggest information of potential interest to them, helping them to limit their searches by providing a number of elements that may be relevant. These alerts provide information and navigation support when you have large volumes of information [27].

In literature and in the market there are different types of recommender systems that differ in the method or process of obtaining the recommendations and / or information sources used. The most general classification is given below:

- collaborative recommender systems [29],

- content-based recommender systems [30]

- knowledge-based recommender systems [31],

- hybrid recommender systems [32]

Interrelationships between decision systems.

To complement this survey regarding the three foundational concepts for the approach presented in this paper, a crossing table is provided as follows in Table No. 1. This table depicts the commonalities among DSS, BI and RS considering their purpose "to support decision making", as well as, their processes, techniques and models. 
Table 1: Comparing DSS, BI and RS.

\begin{tabular}{|c|c|c|c|}
\hline $\begin{array}{r}\text { Perspective } \\
\text { of comparison }\end{array}$ & $\overline{D S S}$ & $\overline{B I}$ & $R S$ \\
\hline Definition & $\begin{array}{l}\text { The DSS are in- } \\
\text { formation technolo- } \\
\text { gy interactive Sys- } \\
\text { tems that help the } \\
\text { persons in charge of } \\
\text { taking decisions us- } \\
\text { ing data and models } \\
\text { to solve non- } \\
\text { patterned problems } \\
\text { [13] }\end{array}$ & $\begin{array}{l}\text { Business intelli- } \\
\text { gence is defined as } \\
\text { the result of "ac- } \\
\text { quisition, interpre- } \\
\text { tation, collation, } \\
\text { assessment, and } \\
\text { exploitation of in- } \\
\text { formation" [21] }\end{array}$ & $\begin{array}{l}\text { RS apply statistical } \\
\text { and knowledge di- } \\
\text { covery techniques to } \\
\text { the problem of mak- } \\
\text { ing product recom- } \\
\text { mendations }\end{array}$ \\
\hline Classification & $\begin{array}{l}\text { Model-driven } \\
\text { Data-driven } \\
\text { Knowledge-driven } \\
\text { Document-driven } \\
\text { Communication- } \\
\text { driven. }\end{array}$ & $\begin{array}{l}\text { BI as a service } \\
\text { Real-time BI } \\
\text { Situational BI } \\
\text { Pervasive BI } \\
\text { Collaborative } \\
\text { [33] }\end{array}$ & $\begin{array}{l}\text { Collaborative } \\
\text { Content-based } \\
\text { Knowledge-based }\end{array}$ \\
\hline $\begin{array}{l}\text { Decision } \\
\text { Processes }\end{array}$ & $\begin{array}{l}\text { Decision Maker } \\
\text { Preferences, } \\
\text { Multicriteria evalua- } \\
\text { tion } \\
\text { Multiobective DM, } \\
\text { Uncertainty. }\end{array}$ & $\begin{array}{l}\text { Measurement of } \\
\text { Key Performance } \\
\text { Indicators, } \\
\text { Real time } \\
\text { Multicriteria Eval- } \\
\text { uation. }\end{array}$ & $\begin{array}{l}\text { Decision Maker Pref- } \\
\text { erences, } \\
\text { Multicriteria Evalua- } \\
\text { tion }\end{array}$ \\
\hline $\begin{array}{l}\text { Techniques } \\
\text { and Models }\end{array}$ & $\begin{array}{l}\text { OLAP, Statistics and } \\
\text { Data mining }\end{array}$ & $\begin{array}{l}\text { OLAP, Statistics } \\
\text { and Data mining, } \\
\text { Scorecards and } \\
\text { Dashboards. }\end{array}$ & $\begin{array}{l}\text { Statistics and Data } \\
\text { mining }\end{array}$ \\
\hline $\begin{array}{l}\text { Geospatial } \\
\text { approach }\end{array}$ & $\begin{array}{l}\text { SDSS - Spatial De- } \\
\text { cision Support Sys- } \\
\text { tems }\end{array}$ & $\begin{array}{l}\text { Geospatial Busi- } \\
\text { ness Intelligence }\end{array}$ & $\begin{array}{l}\text { Context-Aware Rec- } \\
\text { ommender Systems }\end{array}$ \\
\hline
\end{tabular}


The table above depicts the commonalities among DSS, BI and RS considering their purpose to support decision making, processes, techniques and models. The specialization of these technologies into geospatial context is also included at the end of the table.

To compare DSS and BI, the table above assumes the broader perspective of DSS which describe their primary driving sources of information, according to [11] and the data-centric perspective to describe BI [25], [24].

According to [34], BI are data-driven DSS; however they also include OLAP or GIS functionality from the model perspective. From Arnott and Pervan, a DSS includes personal decision support systems, group support systems, executive information systems, online analytical processing systems, data warehousing, and business intelligence [17].

From the point of view of DSS, recommender systems can be understood as tools supporting consumers in their decision making process. Therefore, the ultimate goal of a $\mathrm{RS}$ is to increase the quality of decisions made. A variety of factors actually influence the users of decision making such as their appreciation of the system, trust in the information and service provider, experience and domain expertise, word-of-mouth as well as their real preferences. Some authors see RS as User-facing DSS [35].

Data mining is one of the common techniques used in both context DSS and RS. In the context of recommender applications, the term data mining is used to describe the collection of analysis techniques used to infer recommendation rules or build recommendation models from large data sets. Recommender systems that incorporate data mining techniques make their recommendations using knowledge learned from the actions and attributes of users. These algorithms include clustering, classification techniques, the generation of association rules, and the production of similarity graphs through techniques such as Horting [36].

\section{Context-aware Spatial Decision Support Systems}

This section focuses on conceptual issues of our approach of Context-aware Spatial Decision Support Systems (CA-SDSS).

Previously, the evolution of Geospatial Decision Systems is analyzed with the objective to argument the conceptual framework provided. In the same sense, and in order to demonstrate the own contribution of the author's approach in this paper, related work is also commented.

\section{Evolution of Spatial Decision Systems}

How traditional Decision Support Systems have been progressing in their relation to other decision branches and with the own evolution of Spatial Decision Systems, can be appreciated in the Figure 1 .

To build this picture, the authors were inspired from their own experiences in this field [37], [38], [10] and previous analysis of progression of SDSS and GeoBI [1], [39], [40], [3], [4], [5], [41], enriched by some information extracted from hype-cycles on BI and contextaware technologies provided by Gartner [42].

At a glance, Figure 1 reveals three processes of evolution at horizontal level: (upper) non-spatial Decision Support Systems; (middle) Geographical Information Systems; and (lower) Spatial Decision Support Systems.

However, their individual dynamics are close related each other due to the own evolution of Information Technology, particularly Web and wireless technologies, and also because their dependences of the same techniques like data mining, data warehouse or other statistics. 


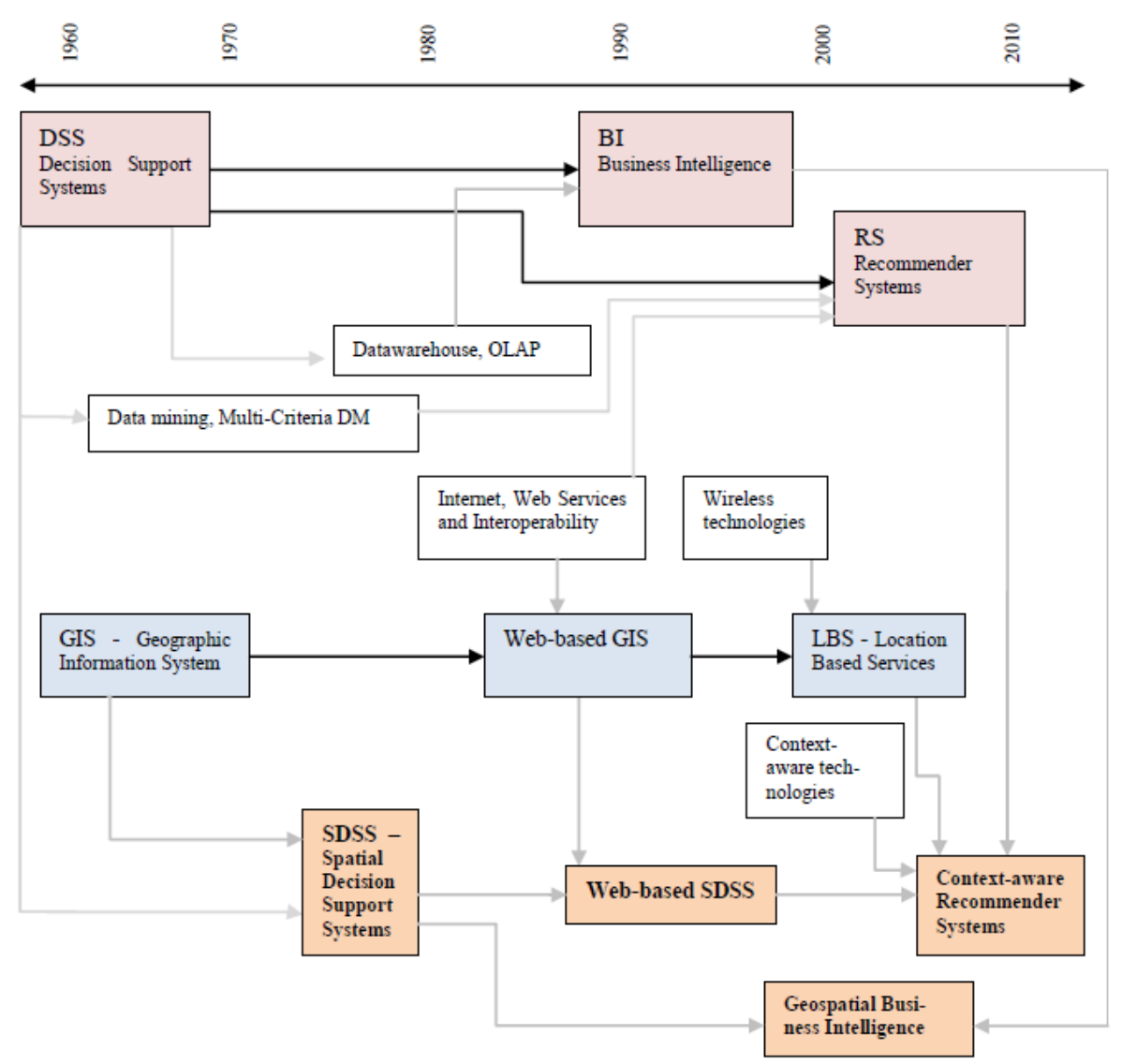

Fig. 1: Evolution of Decision Technologies and Systems toward Geospatial Decision ones.

One interesting reading from the Figure above could be the interdisciplinary relationships between Decision Science and Geographic Information Science, which conditions their connections in each stage.

For the purpose of this paper, special mention deserves the convergence of influences (in the figure expressed as more number of arrows converging in one box) in more recent stages. For instance, Context-aware Recommender Systems (lower-right corner) are benefited from their predecessors in direct line with Recommender Systems, but also from Location Based Services and Web-based Spatial Decision Support Systems.

\section{Related work}

While quite a lot papers focus on Spatial Decision Support Systems [1], [3], [4], [39], [40], [41], the field of context-aware recommender systems (CARS) is a relatively new and underexplored area of research, and much more work is needed to explore it comprehensively [43].

In [5] the authors present a design approach of a Collaborative spatial decision support system (C-SDSS) emphasizing on the premise that knowing stakeholders' concerns can help anticipate user information needs and consequently can guide sys-tem designers in achieving a CSDSS that fits the decision process. This approach can be considered as an embryonic approach of a collaborative Recommender System based on spatial decision support systems.

More recently there are incremental examples of Context-aware Recommender Systems as PILGRIM [44], GeoSocialDB [45], Location-based service recommendation model (LBSRM) [46], Cinemappy: a Context-aware Mobile App for movie recommendations boosted by DBpedia [47], COMPASS [48] and a Mobile Locationbased Information Recommendation System Based on GPS and WEB 2.0 Services proposed in [49], as the most representative ones related to our paper. All of them offer interesting inputs on both theoretical and practical issues. However, the main contribution of our architecture of Context Aware Recommender System (CA-SDSS) is its conceptual model specialized from a SDSS, considering the evolution presented above in the Figure 1. This is important in order to meet for successive approximations to a more generalized model of SDSS which can embrace the other branches of decision systems (Location/Geospatial Business Intelligence, Recommender Systems and Decision Support Systems). 


\section{CA-SDSS architecture}

Intentionally for the purposes of this work, the architecture of CA-SDSS is derived from a general schematic architecture for Decision Support Systems.

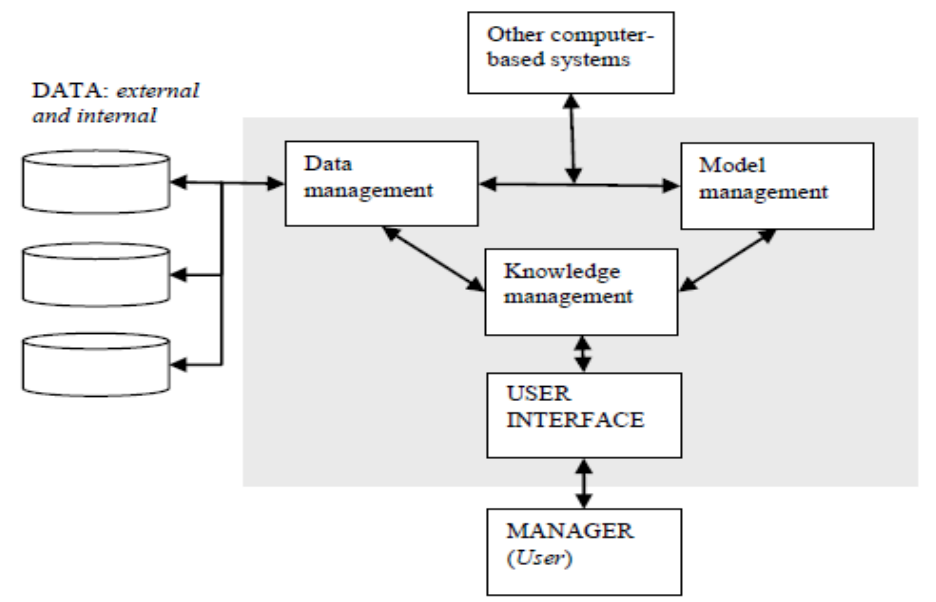

Fig 2: Schematic of components for a decision support system [50]

Following this approach and incorporating the building

based services and map elements, the CA-SDSS architecture is deployed in the Figure 3. blocks of a Recommender System, as well as, location

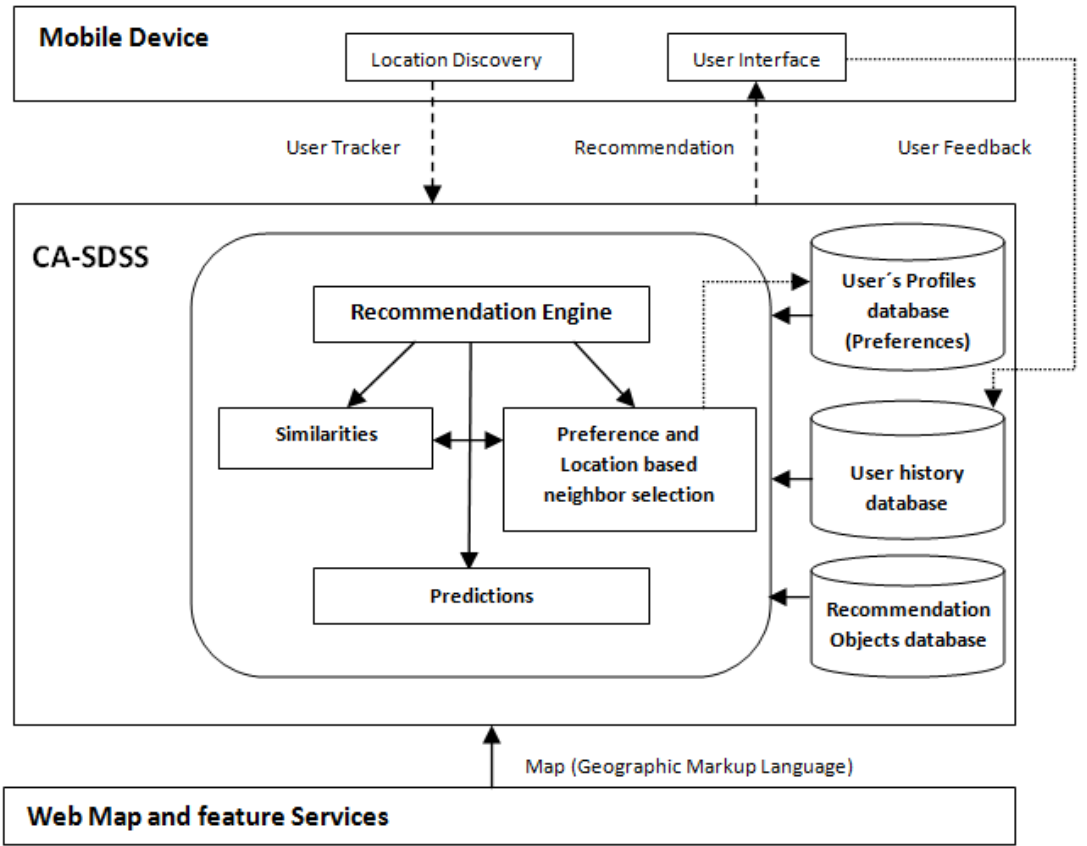

Fig. 3: CA-SDSS architecture

The building blocks of CA-SDSS architecture include:

1. Mobile device: Containing the function of Location Discovery and the Mobile User Interface. This block delivers user positions from the mobile. Visualization functions to show user recommendations are also included on it.

2. CA-SDSS core: Embracing the user databases (user profiles and history) and a repository of objects for recommendations (e.g., points of interests in a tourism application). Within the CA-SDSS 
component, the Recommendation Engine is where the data, model and knowledge are managed. This block interacts with the Mobile Device receiving the User Tracker from Global Positioning Systems and delivering recommendations for users. It is noticeable that there is a feedback from the user with the view to update the user history database and so to allow learning to future recommendations. Internally, the engine use the data necessary to filter and provide the recommendation, applying the suitable statistics functions from collaborative, content and location considerations. CA-SDSS connect also with Web Maps Services (WMS) and/or Web Features Services (WFS), receiving the appropriate geospatial dataset in GML (Geographic Markup Language) syntax, in correspondence with the Open Geospatial Consortium $\left(\mathrm{OGC}^{1}\right)$ interoperability standards ${ }^{2}$.

3. Web Map/Features Services: Are common interoperable services standardizes by OGC, which have been adopted by the global geospatial com-munity. This a crucial issue, considering the importance to keep interoperability with other approaches for flexibility and openness.

Keeping in mind the orientation of this paper to converge towards a generalized framework of Spatial Decision Support Systems considering commonalities and distinctions of DSS, BI and RS, the CA-SDSS, as a Contextaware Location Recommender System, offers a theoretical contribution towards arriving to a more generalized and contemporary SDSS architecture.

So far CA-SDSS is being experimented in a tourism scenario and the first evaluation indicators (dependence of the training set and accuracy of the recommendations, precision tests and recall assessments) are revealing its validity. The results of these experiments will be discussed in next papers.

\section{Conclusions and Future work.}

Analytics considerations regarding commonalities and differences among Decision Support Systems, Business Intelligence and Recommender Systems, as well as, the schematic evolution discussed on these technologies can contribute to understand the emergent necessity to model more generalized frame-works of Spatial Decision Support Systems in order to maximize the benefits by the combination of their strengthens in a unique approach.

CA-SDSS is the first architecture for Context-aware Location Recommender System obtained by the generali-

\footnotetext{
${ }^{1}$ OGC® is a registered trademarks of OGC

${ }^{2} \mathrm{http} / / / \mathrm{www}$.opengeospatial.org/
}

zation of the main components of Decision Support Systems.

This work continues under develop oriented to three fundamental addresses:

- To deepen in theoretical issues of conceptual modeling for Spatial Decision Support Systems, by the aggregation of similar architectures for Geospatial Business Intelligence and Web SDSS considering similar building blocks.

- Implementing the CA-SDSS approach in different cases studies in order to evaluate its viability and validity.

- Incorporating a Semantic component for the general conceptualization of Spatial Decision Support Systems.

\section{References.}

[1] P. J. Densham, "In Geographical Information Systems", Vol. 1, No. 1, pp. 403-412, 1991.

[2] J. Muller, "Latest developments in GIS/LIS," International Journal of Geographical Information Systems, Vol. 7, No. 4, 1993.

[3] C. Rinner, "Web-based Spatial Decision Support: Status and Research Directions," Journal of Geographic Information and Decision Analysis, pp. 14-31, 2003.

[4] V. Sugumaran and R. Sugumaran, "Web-based Spatial Decision Support Systems (WebSDSS): Evolution, Architecture and Challenges," in Third Annual SIGDSS Pre-ICIS Workshop Designing Complex Decision Support: Discovery and Presentation of Information and Knowledge, Las Vegas, Nevada, 2005.

[5] P. Jankowski, S. Robischon, D. Tuthill, T. Nyerges and K. Ramsey, "Design Considerations and Evaluation of a Collaborative, Spatio-Temporal Decision Support System," Transactions in GIS, Vol. 10, No. 3, pp. 335-354, 2006.

[6] W.L. Meeks, and S. Dasgupta, "Decision Support Systems", Decision Support Systems, Vol. 38, pp. 4763, 2004.

[7] A. Aziz Diallo, T. Badard, F. Hubert and S. Daniel, "Mobile and Context-Aware GeoBI Applications: A Multilevel Model for Structuring and Sharing of Contextual Information," Journal of Geographic Information System, Vol. 4, pp. 425-443, 2012.

[8] Open Geospatial Consortium, "Geo-spatial Business Intelligence (GeoBI)", OpenGIS White Paper OGC 09-044r2, 2011.

[9] M. Barranco, J.M. Noguera, J. Castro and L. Martínez., "A Context-Aware Mobile Recommender System Based on Location and Trajectory", Management Intelligent Systems. Advances in Intelligent Systems and Computing, Vol. 171, pp. 153-162, 2012. 
[10] R. González, "El componente semántico en Sistemas de Recomendaciones Sensibles al Contexto," in Proceedings INFORMATICA 2013, La Habana, 2013.

[11]D.J. Power, "Decision support systems: concepts and resources for managers", Decision support systems. Greenwood Publishing Group, pp. 284, 2002.

[12]P. Keen, "Decision support systems: a research perspective." , Massachusetts: Center for Information Systems Research, Sloan School of Management, Massachusetts Inst. of Technol., 1980.

[13] R.H.J. Sprague and E. D. Carlson, "Building effective decision support systems", Prentice Hall Professional Technical Reference, 1982.

[14]P. Finlay, "Introducing decision support systems", NCC Blackwell, 1989.

[15]E. Turban, "Decision Support and Expert Systems: Management Support Systems", Decision Support and Expert Systems., New Jersey: Prentice Hall PTR, 1990.

[16] J.D.C. Little, "Models and Managers: The Concept of a Decision Calculus", Models and Managers // Management Science, Vol. 50, No. 12 Supplements, pp. 1841-1853, 2004.

[17] D. Arnott, and G. Pervan, "A critical analysis of decision support systems research", Journal of information technology, Vol. 20, No. 2, pp. 67-87, 2005.

[18] J. P. Shim, M. Warkentin, J. F. Courtney, D. J. Power and R. Sharda, "Past, present, and future of decision support technology," Decision support systems, Vol. 33, No. 2, p. 111-126, 2002.

[19]D. J. Power and S. Kaparthi, "Building Web-based decision support systems," Studies in Informatics and Control, Vol. 11, No. 4, pp. 291-302, 2002.

[20] T. H. Davenpor, "Competing on Analytics", Harvard Business Review, Vol. 84. No. 1, pp. 98-107, 2006.

[21] P.H.J Davies, "Intelligence, information technology, and information warfare", Annual Review of Information Science and Technology. , Vol. 36, pp. 313352, 2002.

[22] G. J. Miller, B. Dagmar and V. G. Stefanie, "Business intelligence competency centers: A team approach to maximizing competitive advantage", John Wiley and Sons, pp. 256, 2006.

[23] M. Raisinghani, "Business Intelligence in the Digital Economy: Opportunities, Limitations and Risks", Hershey, PA: The Idea Group, 2004.

[24] E. Turban, S. Sharda, J. Aronson, D. King, "Business Intelligence: A Managerial Approach", Pearson Prentice Hall, NJ, 2008.

[25] H. J. Watson, and B. H. Wixom, "The Current State of Business Intelligence", IEEE Computer, Vol. 40, No. 9, pp. 96-99, 2007.

[26] R.L. Sallam, J. Richardson, J. Hagerty and B.Hostmann, "Magic Quadrant for Business Intelligence Platforms", Gartner Group, Stamford, CT. (2011)
[27] R.M. Espinilla, L. Rodríguez, L.G. Martínez, M. Pérez and M. Barranco, "SR-REJA. Sistema de Recomendación Híbrido Georreferenciado", Jaén, España, Congresos. - $2009 \quad$ - 2012. , http://sinbad2.ujaen.es/cod/archivosPublios/publicaci ones/congresos/Espinilla2009_IADIS.pdf.

[28]H. Sacher and G. Loudon, "Uncovering the new wireless interaction paradigm”. Interactions. 20022012 ., vbn.aau.dk/files/74627193/Designing_Mobile_Interac tions_vol_2.pdf.

[29] G. Adomavicius, "Toward the Next Generation of Recommender Systems: A Survey of the State-of-theArt and Possible Extensions", IEEE Transaction On Knowledge And Data Engineering, Vol. 17, No. 6, 2005.

[30]L. Martínez, M.J. Barranco, L.G. Pérez, and M. Espinilla, "A Knowledge Based Recommender System with Multigranular Linguistic Information", International Journal of Computational Intelligence Systems, Vol. 1, No.3, 2008.

[31]R. Burke, "Knowledge-Based Recommender Systems", Encyclopedia of Library and Information Systems, 2000.

[32]R. Burke, "Hybrid Recommender Systems: Survey and Experiments", User Modeling and User-Adapted Interaction, 2002.

[33] S. Rizzi, "Collaborative Business Intelligence". In Aufaure, M., Zimanyi, E., eds.: eBISS 2011, Vol. LNBIP 96, pp.186-205, 2012.

[34] D. Power, "A brief history of decision support systems", DSSResources.com, http://DSSResources. com/history/dsshistory.html, Vol. 4, 2007.

[35] M. Hashler, "Recommender Systems. User-facing Decision Support Systems", Publications and talks. , February 2012. - June 2013. http://michael.hashler.net.

[36] J. Schafer, "The application of data-mining to recommender systems." Encyclopedia of data warehousing and mining, Vol. 1, pp. 44-48, 2003.

[37] T. Delgado, "Sistemas de Soporte a la Decisión y Sistemas de Información Geográfica en interés de la Agricultura", La Habana: Instituto Superior Politécnico José A. Echeverría, 1997.

[38] T. Delgado, G. Miranda and A. Graveran, "Toward the development of geospatial business intelligence", Proceedings INFORMATICA 2013. - La Habana: [s.n.], 2013.

[39] K. C. Clarke, Getting Started with Geographic Information Systems, New Jersey: Prentice Hall, 1997.

[40] J. Malczewski, "Spatial Decision Support Systems", NCGIA Core Curriculum in GIScience, 1997. - January 20012, 2012. http://www.ncgia.ucsb.edu/giscc/units/u127/u127.htm 1.

[41] J. Sornig, "Development of a Distributed Service Framework for Location-based Decision Support", 
MSc thesis. - Carinthia University of Applied Sciences/School of Geoinformation, 2008.

[42] Gartner, "Gartner's Hype Cycle Special Report for 2010", Gartner. Publication Date: 5 August 2010/ID Number: G00205839, 2010.

[43] G. Adomavicius, "Context-Aware Recommender Systems," in Recommender Systems Handbook, Springer, 2010.

[44] M. Brunato, "PILGRIM: A location broker and mobility-aware recommendation system," in Pervasive Computing and Communications, 2003. (PerCom 2003). Proceedings of the First IEEE International Conference on, pp. 265-272. IEEE, 2003.

[45] M. Mokbel, J. Bao, A. Eldawy, J. Levandoski and M. Sarwat, "Personalization, Socialization, and Recommendations in Location-based Services 2.0." In 5th International VLDB workshop on personalized access, Profile Management and context awareness in Databases (PersDB). VLDB. , 2011.

[46] M.H. Kuo, L. C. Chen and C. W. Liang, "Building and evaluating a location-based service recommenda- tion system with a preference adjustment mechanism" Expert Systems with Applications, Vol. 36, No. 2, pp. 3543-3554, 2009.

[47] V.C. Ostuni, T. Di Noia, R. Mirizzi, D. Romito and E. Di Sciascio, "Cinemappy: a Context-aware Mobile App for Movie Recommendations boosted by DBpedia," SeRSy, pp. 37-48, 2012.

[48] M. Van Setten, S. Pokraev and J. Koolwaaij, "Context-aware recommendations in the mobile tourist application COMPASS," in Adaptive hypermedia and adaptive web-based systems, Springer Berlin Heidelberg, pp. 235-244, 2004.

[49]F. Yang and Z. Wang, "A mobile location-based information recommendation system based on GPS and WEB 2.0" Database, Vol. 7, No. 8, 2009.

[50]A. Bello-Dambatta, "The Development of a Webbased Decision Support System for the Sustainable Management of Contaminated Land," PhD diss., University of Exeter, 2010. 